\title{
CAMPANHAS DE COMBATE AO AEDES AEGYPTI \\ NA REGIÃO AMAZÔNICA: UMA ANÁLISE DE ATENÇÃO VISUAL COM O USO DO EYE TRACKER
}

\author{
Campaigns to combat Aedes aegypti in the Amazon region: an \\ analysis of visual attention with the use of eye tracker
}

\section{Campañas de combate al Aedes aegypti en la región amazónica: un análisis de la atención visual con el uso del eye tracker}

\author{
Diogo Rógora Kawano \\ Instituto Federal do Amapá, Santana, Amapá, Brasil. \\ Professor do Instituto Federal do Amapá. Doutorando do Programa de Pós-Graduação em Ciências da \\ Comunicação da Universidade de São Paulo. Membro do Centro de Comunicação e Ciências Cognitivas da \\ Escola de Comunicações e Artes da Universidade de São Paulo. \\ E-mail: drkawano@gmail.com.
}

\section{Ana Clara Amorim Jardim}

\author{
Universidade de São Paulo, São Paulo, São Paulo, Brasil. \\ Discente do curso de Publicidade e Propaganda da Escola de Comunicações e Artes da Universidade de \\ São Paulo. \\ E- mail: anaclara_jardim@hotmail.com.
}

\section{Marcia Shimabukuro \\ Universidade de São Paulo, São Paulo, São Paulo, Brasil. \\ Discente do curso de Publicidade e Propaganda da Escola de Comunicações e Artes da Universidade de São Paulo. \\ E- mail: marcia.shimabukuro@usp.br}

\section{Luan Matheus Gonçalves Rodrigues \\ Instituto Federal do Amapá, Santana, Amapá, Brasil. \\ Discente do curso de Marketing do Instituto Federal do Amapá. \\ E-mail: luanmgr@gmail.com}

\section{Leandro Leonardo Batista}

Universidade de São Paulo, São Paulo, São Paulo, Brasil.

Professor doutor em Comunicação Social pela University of North Carolina. Docente da Escola de Comunicações e Artes da Universidade de São Paulo. Membro do Centro de Comunicação e Ciências Cognitivas da Escola de Comunicações e Artes da Universidade de São Paulo.

E-mail: leleba@usp.br.

RESUMO Além de duas importantes doenças endêmicas presentes no Brasil (dengue e chikungunya), o país tem enfrentado nos últimos anos outro problema atrelado ao mosquito Aedes aegypti: o Zika vírus e uma de suas consequências, a microcefalia. Nesse cenário, embora haja muitos desafios, a comunicação de risco emerge enquanto estratégia fundamental para auxiliar no combate a essas doenças. Este trabalho tem o objetivo de analisar como as campanhas de combate ao mosquito Aedes aegypti veiculadas na região amazônica são percebidas pelos indivíduos. Para tanto, observou-se, com o auxílio do equipamento de rastreamento ocular eye tracker, de que modo alguns elementos da campanha, como título do anúncio, imagens e textos, além da identificação dos anunciantes, foram capazes de atrair a atenção visual dos participantes. Os principais resultados mostram que a saliência dos elementos, associada à sua forma de disposição na campanha, foram capazes de modular a atenção visual dos 
participantes, evidenciando que (i) a metodologia do eye tracking se mostrou assaz pertinente para os estudos de comunicação de risco e (ii) há gargalos no processo de planejamento desses conteúdos, que impactam diretamente a atenção dada a eles.

PALAVRAS-CHAVE Comunicação de risco, Eye tracking, Zika, Campanhas de saúde pública, Publicidade.

ABSTRACT In addition to two important endemic diseases present in Brazil (dengue and chikungunya), the country has faced in recent years another problem linked to the mosquito Aedes aegypti: the Zika virus and one of its consequences, microcephaly. In this scenario, despite its many challenges, risk communication emerges as a key strategy to assist in the fight against these diseases. This article aims to analyze how campaigns advertised in the Amazon region to combat the Aedes aegypti mosquito are perceived by individuals. To do so, it was observed, with the aid of eye tracker, how elements of the campaign, such as the title, images, and texts, besides the identification of the advertisers, were able to attract the visual attention of the participants. The main results show that the saliency of the elements, associated with their disposition in the campaign, were able to modulate the visual attention of the participants, evidencing that (i) the eye tracking methodology was pertinent to the studies of risk communication and (ii) there are bottlenecks in the planning process for these contents, which directly impact the attention given to them.

KEYWORDS Risk communication, Eye tracking, Zika, Public health campaigns, Advertising.

RESUMEN Además de dos importantes enfermedades endémicas presentes en Brasil (dengue y chikungunya), el país ha enfrentado en los últimos años otro problema relacionado al mosquito del Aedes aegypti: el virus Zika y una de sus consecuencias, la microcefalia. En este escenario, aunque hay muchos desafíos, la comunicación de riesgos surge como una estrategia fundamental para ayudar en la lucha contra estas enfermedades. Este trabajo tiene el propósito de analizar cómo las campañas para combatir el mosquito Aedes aegypti difundidas en la región amazónica son percibidas por los individuos. Para ese propósito se observó, con la ayuda del eye tracker, cómo algunos elementos de la campaña, como el título del anuncio, imágenes y textos, además de la identificación de los anunciantes, fueron capaces de atraer la atención visual de los participantes. Los resultados principales demuestran que el destaque de los elementos, asociado a su forma de disposición en la campaña, había sido capaz de modular la atención visual de los participantes, evidenciando que (i) la metodología del eye tracking se mostró pertinente para los estudios de la comunicación de riesgo y (ii) hay obstáculos en el planeamiento de este contenido que impactan directamente en la atención dada a la campaña.

PALABRAS CLAVE Comunicación de riesgo, Eye tracking, Zika, Campañas de salud pública, Publicidad.

\section{INTRODUÇÃO}

Com o objetivo de acompanhar as mudanças societais e seus impactos em um complexo cenário de consumo, pautado cada vez mais por uma dinâmica de forte concorrência, muito se tem discutido e estudado sobre as campanhas mercadológicas, cujas marcas e anunciantes tentam se expressar de diversas formas e estabelecer pontos de contato nos distintos modos de publicização que gerem uma sintonia mais fortalecida com seus públicos de interesse (CASAQUI, 2011; DI NALLO, 1999; PEREZ, 2004).

Entretanto, quando a comunicação adquire uma dimensão social, como no caso das campanhas de saúde pública, nota-se que os processos comunicacionais ainda carecem de um olhar mais aprofundado (SILVA; MAZZON, 2015), que leve em consideração a natureza e a importância 
da mensagem em questão, sobretudo quando o problema abrange todo o Brasil e impacta diretamente regiões com menor desenvolvimento social e econômico, como é o caso do Norte do país.

É precisamente nesse sentido que este trabalho objetiva analisar como campanhas de combate ao mosquito Aedes aegypti veiculadas na região Norte são percebidas pelos indivíduos. De forma mais específica, observou-se, com o auxílio do eye tracker, de que modo elementos da campanha, como título do anúncio, imagens e textos, além da identificação dos anunciantes, foram capazes de atrair a atenção visual dos participantes.

Para tanto, são apresentados e discutidos, no referencial teórico, os conceitos atrelados a esse processo comunicacional, como risco percebido e comunicação de risco. São expostos, também, os problemas associados ao mosquito Aedes aegypti no país, e explana-se a técnica de rastreamento ocular, o eye tracking. Na sequência, são detalhados os procedimentos metodológicos, cujos resultados e discussão são apresentados de forma dividida (qualitativos e quantitativos) na seção 4. Por fim, são expostas as considerações finais desta pesquisa.

\section{A PERCEPÇÃO DE RISCO E O COMBATE AO AEDES AEGYPTI}

O conceito de risco percebido é de fundamental importância para os estudos em comunicação, uma vez que ele adquire distintas dimensões, consoante o tema em questão. Assim, tem-se que risco percebido é a tipologia de risco subjetivamente identificada pelas pessoas e independente da probabilidade real verificada no risco objetivo (BEIL, 2007, p. 13).

Dessa forma, os perigos associados a uma doença, por exemplo, podem ser percebidos de modo (i) subestimado, fazendo que determinada população não adote medidas para combater o vetor da doença, o Aedes aegypti, ou (ii) superestimado, como um hipotético caso de mortes pelo vírus H1N1, que gere pânico na sociedade, a qual passa a se sentir ameaçada de forma desproporcional às reais probabilidades de contaminação e eventual óbito.

Campanhas como as estudadas neste trabalho pertencem a uma categoria denominada comunicação de riscos, que, por sua vez, é entendida como "um processo interativo de troca de informação e opiniões entre indivíduos, grupos e instituições, envolvendo mensagens que expressam a natureza do risco e preocupações decorrentes da percepção de uma determinada situação" (NATIONAL RESERACH COUNCIL, 1989). Pelo fato de essas campanhas lidarem com problemas de grande relevância relacionados à saúde e ao comportamento, elas devem ser concebidas e executadas com especial atenção, pois, diferentemente de campanhas mercadológicas, nas quais se anuncia um produto ou serviço, a comunicação de risco não pode estar sujeita a erros que levem o público a não adotar o que é sugerido ou, ainda, a adotar um comportamento equivocado, o que poderia causar grandes prejuízos à sociedade.

Explorando o percurso histórico de combate ao mosquito Aedes aegypti, pode-se destacar as três doenças de maior relevância no cenário nacional: dengue, febre chikungunya e zika, esta com consequências que vão além da enfermidade em si.

A dengue, em especial, está presente no Brasil há várias décadas, mas tem adquirido uma dimensão de grande preocupação epidemiológica a partir da década de 1990 (ALECRIM; COTTA; CASTRO, 2016). Somente 
de janeiro a abril de 2016, houve quase 1,2 milhões de casos prováveis da doença em todos o país, com redução de mais de $90 \%$ no mesmo período de 2017, creditada, principalmente, à escassez de chuvas em algumas regiões e à maior proteção adquirida em casos anteriores da doença (BRASIL, 2017). Ainda segundo o boletim epidemiológico do mesmo período, o Norte figura como a região com a segunda maior taxa de incidência: 89,4 casos/100 mil habitantes, atrás apenas da região Centro-Oeste, com 160 casos/100 mil habitantes.

Dentre as características e consequências mais evidentes da dengue, tem-se o fato de ela ser uma virose grave e passível de ser adquirida várias vezes (ALECRIM; COTTA; CASTRO, 2016), fazendo que os custos sociais e econômicos atrelados à doença sejam altos, dado que, mesmo contaminado pela forma menos grave, o indivíduo necessita de repouso por vários dias (FERREIRA; CHIARAVALLOTI-NETO; MONDINI, 2016).

A febre chikungunya tem como sintoma característico fortes dores nas articulações, em especial, das mãos e dos pés. A circulação da doença no Brasil foi identificada, pela primeira vez, em 2014, embora sua primeira epidemia no mundo tenha sido registrada já na década de 1950, no leste da África (MINISTÉRIO DA SAÚDE, 2016). Em 2016, foram mais de 250 mil os casos da doença no país (aumento de $850 \%$ em relação a 2015), com 138 mortes.

O terceiro e mais recente problema epidemiológico relacionado ao Aedes Aegypti é o Zika vírus, cuja presença no país foi identificada, pela primeira vez, em 2015 (MINISTÉRIO DA SAÚDE, 2016). Apesar de $80 \%$ dos indivíduos infectados pelo vírus não apresentarem sintomas clínicos, o que é, ao mesmo tempo, positivo (pela ausência de sintomas) e negativo (pela dificuldade de diagnóstico preciso), há grande preocupação com mulheres gestantes contaminadas, situação que pode resultar na microcefalia dos bebês (malformação congênita, em que o cérebro não se desenvolve totalmente, ocasionando um perímetro encefálico menor do que o considerado normal pela Organização Mundial da Saúde). Desde novembro de 2015, quando os problemas de microcefalia começaram a aumentar, até o final de 2016, houve 2.205 casos confirmados em todo o país, com prevalência nos estados da região Nordeste.

Por conseguinte, nota-se que o controle dessas doenças é complexo, pois necessita do envolvimento ativo da população associado às ações do governo (FERREIRA, 2003), sejam elas políticas de saúde pública, educação ambiental, campanhas de combate ao mosquito, ou outras.

\section{O EYE TRACKER COMO METODOLOGIA DE PESQUISA EM COMUNICAÇÃO}

O eye tracking consiste em uma técnica que faz o rastreamento ocular do indivíduo diante de um estímulo visual, o qual pode ser estático (campanha impressa) ou dinâmico (campanha audiovisual veiculada na televisão ou em redes sociais). Embora essa técnica seja estudada no âmbito científico desde o início do século XX (ROBINSON, 1968), ganhou considerável força nas últimas décadas, sobretudo devido (i) ao avanço tecnológico, que permitiu formas de coleta mais rápidas e precisas, e (ii) à apropriação de seus fundamentos por diversas esferas do conhecimento, como a medicina, psicologia, educação, linguística, economia e comunicação (LIVERSEDGE; GILCHRIST; EVERING, 2011). 
Especificamente na comunicação, o uso dessa metodologia se mostra assaz pertinente, na medida em que permite identificar os pontos de determinada peça de comunicação que mais chamaram a atenção do público-alvo (logomarca, texto escrito, imagem do produto ou do modelo, etc.). Além dessa informação objetiva - o tempo de visualização, geralmente dado em segundos ou milissegundos -, o eye tracking fornece outras métricas, como a ordem de visualização dos elementos e a quantidade de vezes que eles foram visualizados (quantidade de fixações).

Por conseguinte, nota-se que essa metodologia se mostra cientificamente profícua, pois, além de não estar sujeita a vieses inerentes às formas declarativas de coleta de dados, como esquecimento ou repostas socialmente desejadas (MATTAR, 1997: SMITH, 2011), ela permite relacionar processos cognitivos complexos, como percepção, atenção e memória (LIVERSEDGE; GILCHRIST; EVERING, 2011), que também são de fundamental importância para o campo.

Embora a literatura que analisa campanhas de saúde com a metodologia do eye tracker seja bastante restrita ${ }^{1}$, é possível apresentar estudos no campo da comunicação que o fizeram, a fim de elucidar os aspectos de percepção e as métricas principais envolvidas nesse tipo de aferição da atenção visual.

A complexidade de informações com as quais os indivíduos se deparam ao visualizar um conteúdo é um dos aspectos estudados em comunicação. Pieters, Wedel e Batra (2008) utilizaram 249 anúncios diferentes para análise com a técnica do eye tracker, e constataram que altos níveis de complexidade visual geraram menor tempo de visualização da marca, além de um impacto atitudinal negativo em relação ao anúncio. Em uma perspectiva semelhante, mais de uma década antes, Janiszewski (1998) verificou que os elementos situados em um contexto de maior competição visual foram menos percebidos e lembrados do que itens submetidos a uma menor competição atencional.

Outras características de composição do anúncio sugerem, também, impacto no potencial de captura atencional por parte dos indivíduos. Pieters e Wedel (2004) aferiram em seu estudo que, para cada $1 \%$ de aumento da área de anúncio impresso, houve um aumento de $0,81 \%$ no tempo de visualização. No que se refere à atenção dada à parte textual de uma propaganda, a relação é praticamente proporcional: um aumento de 1\% na área do texto ocasionou incremento de 0,9\% da atenção dada a esse elemento.

Ainda no aspecto textual, Rosbergen, Pieters e Wedel (1997) verificaram que o título recebe maior atenção visual que o corpo do texto (geralmente apresentado em tamanho menor, embora contenha mais informações). De forma complementar, Leven (1991) indicou que as pessoas tendem a rapidamente direcionar o olhar para o canto superior esquerdo do anúncio, local onde geralmente se encontra o título, o que pode sugerir uma explicação para tal resultado.

A localização dos elementos também se apresenta como um fator de influência sobre a atenção visual. Nesse sentido, há estudos pioneiros que se dedicaram a compreender esse efeito em diversos aspectos, como a posição de logomarcas em comerciais televisivos, o enquadramento

1. Levantamento realizado com os termos "campaign", "dengue" e "eye tracker" em duas das maiores bases de dados, Scopus e Web of Knowledge, não trouxe resultados em nenhuma parte da série histórica. 
de placas de anunciantes em jogos de futebol e a disposição de banners em páginas da internet (BRASEL; GIPS, 2007; TEIXEIRA et al., 2008; D'YDEWALLE; TAMSIN, 1993; GOLDBERG, 1999; DREZE; HUSSHERR, 2003). Apesar de apresentarem peculiaridades em seus resultados, em geral, os estudos sugerem que a organização da cena impacta diretamente a forma como a atenção visual é distribuída, sendo a posição central uma das mais privilegiadas.

Por fim, as imagens presentes nas campanhas são, em geral, muito exploradas pelas agências e demais produtores de conteúdo, pelo fato de conseguirem captar a atenção das pessoas com mais facilidade. De fato, a literatura aponta tal potencial, mas ainda há muitos aspectos a serem melhor compreendidos nesse âmbito. Um dos achados interessantes nessa linha é a contribuição de Maia (2008), que mostrou que imagens de humanos têm maior potencial de captar atenção, seguidas pelas de animais e, finalmente, de seres inanimados. Ainda, diferentemente do que ocorre com o texto, Pieters e Wedel (2004) verificaram, em seu estudo, que o aumento da imagem em um anúncio praticamente não altera a atenção dada a ela ou à peça publicitária como um todo.

\section{METODOLOGIA}

Para elucidar os pontos discutidos e tendo em vista o objetivo deste trabalho, foi realizado um experimento utilizando a metodologia do eye tracking. $\mathrm{O}$ estudo foi conduzido nas dependências do laboratório 4C - Centro de Comunicações e Ciências Cognitivas da USP -, na Cidade Universitária de São Paulo, durante os meses de maio e junho de 2017, e consistiu na apresentação e análise de cinco peças pertencentes a campanhas de combate ao mosquito Aedes aegypti veiculadas na região amazônica: (i) campanha do governo do Amazonas (SUSAM); (ii) campanha da prefeitura de Igarapé-Miri (PA); (iii) campanha do governo do estado do Pará; (iv) campanha do Tribunal de Justiça do Amapá (AP); e (v) campanha nacional do Ministério da Saúde - SUS. A escolha das peças se deu por conveniência, desde que retratassem a problemática do mosquito ou de alguma das doenças a ele associadas: dengue, zika ou chikungunya.

Participaram do experimento doze estudantes universitários de ambos os sexos, com idade média de 21,9 anos $(\mathrm{dp}=6,4)$. Cada participante visualizou as cinco campanhas, totalizando sessenta peças analisadas. Os estímulos foram apresentados de forma aleatória aos participantes, a fim de anular possíveis efeitos de ordem de apresentação. Entre cada estímulo, uma tela preta com uma cruz branca no centro foi apresentada por um segundo. Não houve um tempo de exposição fixo, bastando ao participante pressionar a tecla "espaço" para encerrar a visualização da peça.

O experimento foi elaborado no software Tobbi Studio ${ }^{\circledR}$ versão 3.4.2. A coleta se deu através do equipamento de rastreamento ocular Eyetracker Tobii X2-60 ${ }^{\circledR}$, posicionado na base de um monitor LCD de dezenove polegadas, a uma distância de $65 \mathrm{~cm}$ dos participantes. As condições de luminosidade do ambiente foram controladas e mantidas estáveis. Os resultados também foram extraídos do software Tobbi Studio ${ }^{\circledR}$ e se subdividem nas formas qualitativa e quantitativa.

Nesse sentido, é importante ressaltar que, apesar da apresentação de alguns dados numéricos, esta pesquisa é de natureza exploratória 
e não tem, portanto, objetivo de extrapolação e inferência dos dados (SAMPIERI; COLLADO; LUCIO, 2013, p. 99), mas, sim, o de verificação de aspectos-chave que subjazem a atenção visual da tipologia de campanhas públicas.

\section{RESULTADOS E DISCUSSÃO}

Para melhor estruturar a apresentação dos resultados, fez-se a divisão desses em duas etapas. Na primeira, será exposta a análise qualitativa, obtida a partir da visualização agregada dos resultados dos participantes a cada uma das peças. Essa análise é pautada em heat maps ou mapas de calor, que explicitam os elementos do anúncio visualizados por mais tempo. A segunda etapa consistirá na apresentação comparativa e numérica entre títulos, imagens principais e identificação do anunciante nas campanhas.

\section{Análise qualitativa da atenção visual}

A primeira campanha, veiculada pelo governo do Amazonas, seguiu uma estratégia de abordagem que se assemelha à mercadológica (Figura 1). Tal fato é especialmente evidenciado no título "Arrasadora liquidação!" e nas frases que o seguem: "É pra acabar! Não vai sobrar um!”. Além disso, tal como uma prática de comunicação promocional mercadológica, a peça utiliza cores quentes, como vermelho e amarelo. No centro, a imagem do mosquito Aedes aegypti se apresenta como um produto a ser "liquidado". Na região inferior do anúncio, são apresentadas cinco iconografias de objetos e plantas que tipicamente acumulam água parada, seguidas por recomendações sobre o que fazer em cada caso. A parte final da peça contém o texto "Dengue mata", com indicação dos principais sintomas da doença e, no canto inferior direito, as logomarcas dos órgãos anunciantes da campanha.

A análise da distribuição da atenção visual dos participantes (Figura 1) mostra que praticamente todos os elementos da campanha foram visualizados, sendo que a imagem central do mosquito obteve maior atenção, resultado semelhante ao verificado por Dreze e Hussherr (2003), e por Brasel e Gips (2007). Ademais, o texto em caixa alta e negrito "É pra acabar! Não vai sobrar um!” foi capaz de captar mais atenção do que o próprio título da campanha, possivelmente por sua saliência visual, como já discutido por Krugman e colaboradores (1994).

Ainda, pode-se notar que o último ícone da sequência horizontal, que retrata a limpeza das calhas, foi menos percebido que os demais. De forma semelhante, a primeira logomarca do anunciante SUSAM foi mais visualizada do que aquela que possui a bandeira do Amazonas. Não obstante, de modo geral, a análise qualitativa mostra que a campanha não apresentou grandes problemas no que se refere à confusão de leitura em virtude do layout, fato bastante distinto da próxima campanha analisada.

A segunda peça, veiculada pela prefeitura municipal de IgarapéMiri (PA) em conjunto com outros cinco parceiros, apresenta grande quantidade de pontos que demandam a atenção dos participantes. Isso pode ser explicado pelo fato de que praticamente toda a área da peça, cujo título é "Toda hora é hora de combater a dengue", está ocupada por textos ou imagens (Figura 2), o que dificulta uma orientação da atenção e uma hierarquização que facilite o entendimento da mensagem pelo público-alvo. 

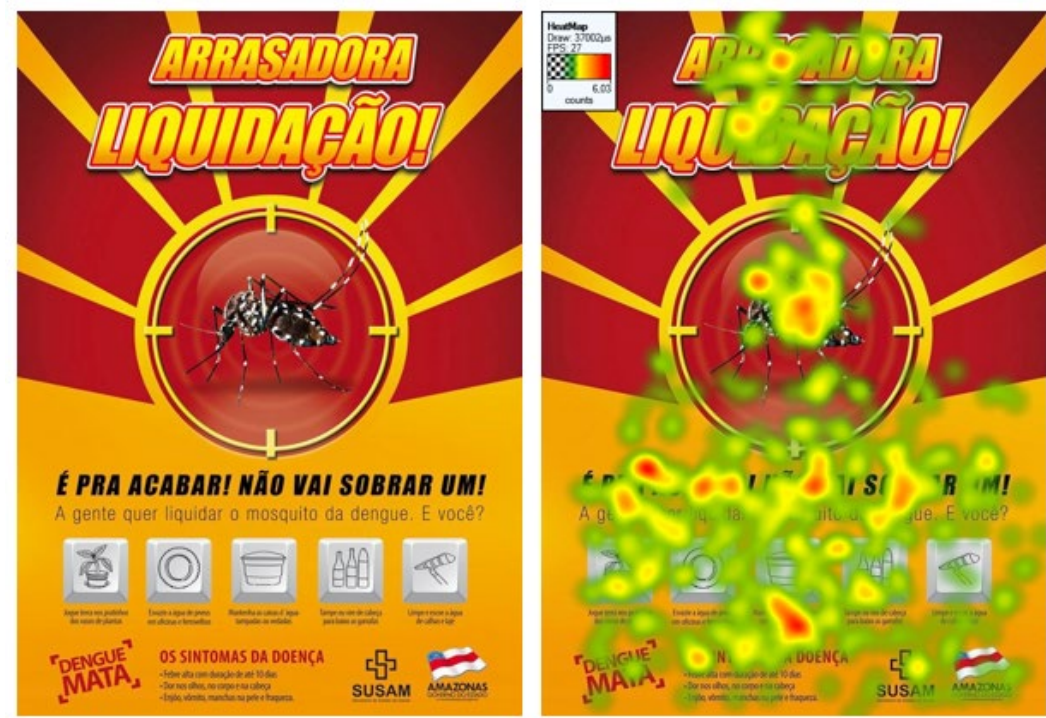

Figura 1 - À esquerda, campanha veiculada pelo governo do Amazonas - SUSAM. À direita, heat map da atenção visual dos participantes.

À esquerda, há duas imagens do mosquito Aedes aegypti; a primeira, sem texto ao redor, passa praticamente desapercebida diante dos outros elementos da peça. A região central do anúncio é ocupada por doze blocos de texto e mais dez ilustrações de possíveis criadouros do mosquito. Todos eles recebem atenção visual breve, pouco concentrada e bem difusa (Figura 2), o que é evidenciado pela grande quantidade de pontos verdes e quase total ausência de pontos vermelhos no heat map da região.

À direita, há dois blocos de informação. 0 primeiro contém um texto na cor preta, sobre um fundo branco, e suas primeiras linhas ganham mais atenção do que as últimas, expondo um "pulo" de leitura feito pelos participantes. O segundo bloco organiza os seis órgãos responsáveis pelo anúncio. Nesse caso, nota-se um claro efeito na ordem das logomarcas expostas: a primeira, posicionada no canto superior esquerdo do bloco, recebe grande quantidade de atenção, seguida pela imagem imediatamente inferior a ela. Tal aspecto pode ser explicado pela possível percepção agrupada do conjunto de anunciantes, formando um novo bloco de informações, que passou a ser observado de forma isolada e, portanto, com início da leitura no canto superior esquerdo e fim na região inferior direita. Os anunciantes inseridos nesse intervalo foram muito pouco visualizados, o que explicita o impacto da marca/instituição no público-alvo.
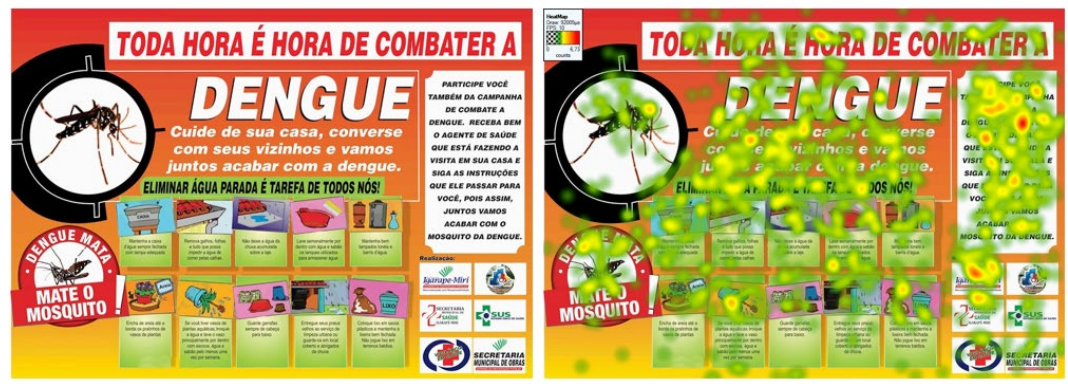

Figura 2 - À esquerda, campanha veiculada pela Prefeitura Municipal de Igarapé-Miri (PA). À direita, heat map da atenção visual dos participantes. 
A terceira peça foi veiculada pelo governo do estado do Pará (Figura 3). Nela, há o argumento central de que "10 minutos contra o Aedes aegypti" (título) despendidos, por semana, em algumas ações são capazes de salvar vidas. Embora, semelhantemente à campanha anterior, quase toda a sua área seja ocupada por textos ou imagens, neste caso as informações estão dispostas em um layout mais organizado: título e imagem na região superior da peça; texto explicativo e iconografias na região central; e contatos para mais informações na parte final do anúncio, na região inferior, que também inclui o texto e a imagem do anunciante, a Secretaria de Saúde do Pará.

Em relação aos resultados qualitativos, nota-se que foi dada maior atenção à região superior da campanha, onde há o título, a imagem do mosquito sobreposta por um sinal de negação na cor vermelha, e o texto complementar: "Com estas ações não levará mais que 10 minutos por semana para salvar vidas, inclusiva a sua."

Outros dois aspectos relevantes são: (i) os itens da coluna esquerda da peça ganharam mais atenção que os da direita, indicando descontinuidade na leitura, a qual foi iniciada pelos itens à esquerda; (ii) pouca atenção despendida na logomarca do anunciante, no centro da região inferior do anúncio, evidenciando os apontamentos discutidos por Lans e colaboradores (2008) de que a atenção é passível de ser guiada pela organização dos elementos de uma cena.

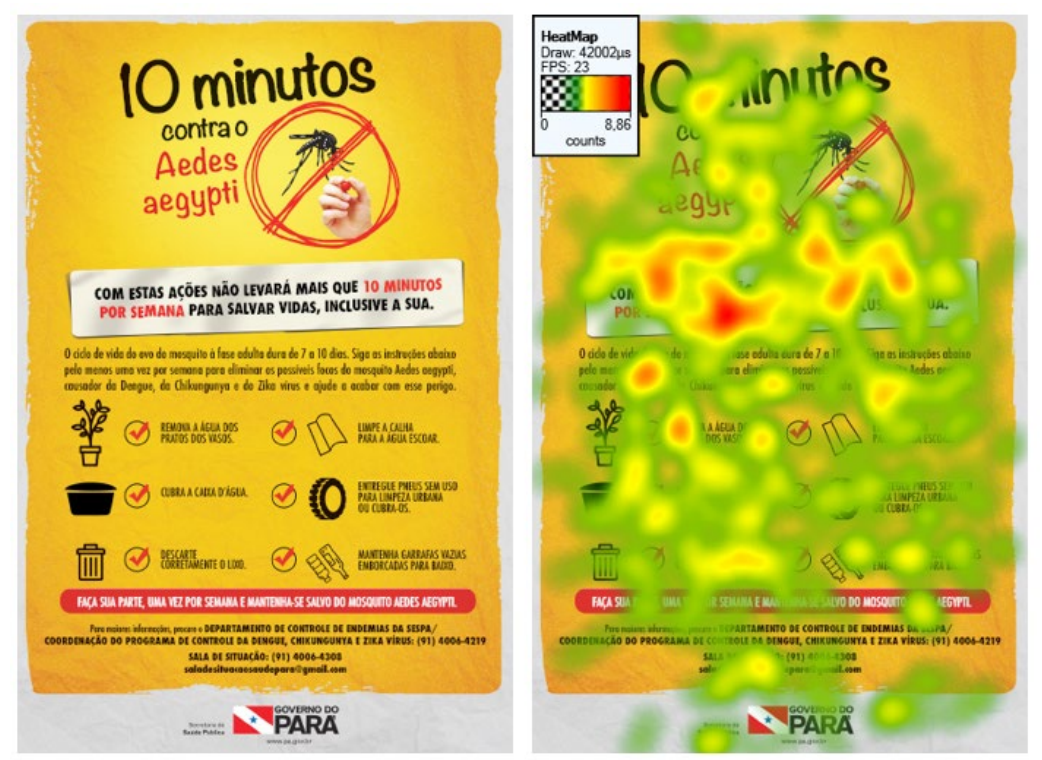

Figura 3 - À esquerda, campanha veiculada pelo governo do estado do Pará. À direita, heat map da atenção visual dos participantes.

A quarta campanha é de responsabilidade do Tribunal de Justiça do Amapá, e possui uma caracterização visual análoga a uma placa de trânsito (Figura 4). Diferentemente das outras peças, o anunciante é indicado em primeiro lugar, centralizado na região superior.

O título, em amarelo sobre uma faixa preta, denota a seguinte mensagem: "O mosquito é pequeno. A consequência é grande". $\mathrm{Na}$ região central, de cor predominantemente amarela, há o texto "todos juntos contra" e a ilustração do mosquito visto de cima, sobreposta por um sinal de negação na cor vermelha semelhante a uma placa de trânsito. Outra faixa preta com o texto "o Aedes aegypti” encerra a parte inferior da campanha. 
Analisando o heat map (Figura 4), é possível observar que a maior atenção ficou concentrada na imagem central, isto é, no mosquito, e, em seguida, na primeira parte do texto (região superior do anúncio). O tamanho e a localização privilegiada do anunciante fizeram que sua logomarca fosse notada sem dificuldade. Por fim, o nome do mosquito, indicado na última faixa da peça, recebeu pouca atenção dos indivíduos, embora tenha sido apresentado em tamanho consideravelmente grande. A análise numérica de atenção visual desses elementos, discutida posteriormente, ajudará a elucidar esses pontos.
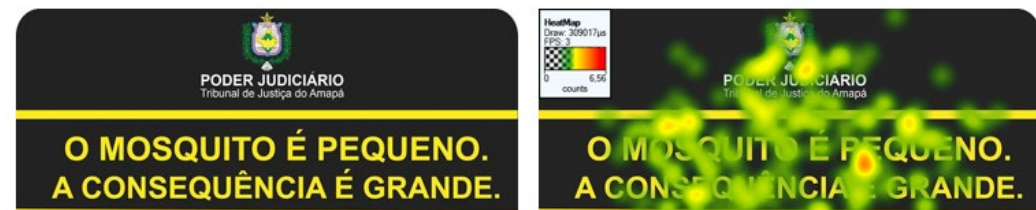

O MOSQUITO É PEQUENO.

A CONSEQUÊNCIA É GRANDE.

TODOS JUNTOS

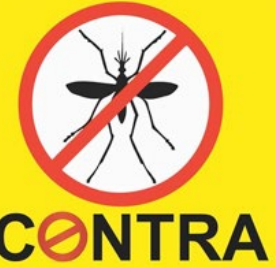

TODUS IINNTOS

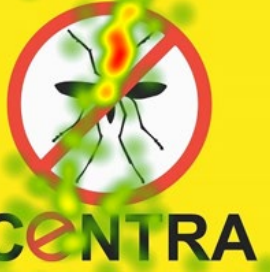

O AEDES AEGYPTI O AEDES AEGYPTI

Figura 4 - À esquerda, campanha veiculada pelo Tribunal de Justiça do Amapá (AP). À direita, heat map da atenção visual dos participantes.

A última peça faz parte de uma campanha veiculada pelo governo federal (Figura 5), e é a que apresenta um layout com mais espaços vazios dentre todas as campanhas analisadas.

O título, redigido em caixa alta e na cor em branca, está sobre uma faixa vermelha, com o texto "Dengue e chikungunya", seguido pelo subtítulo: “O perigo aumentou. E a responsabilidade de todos também”. No centro do anúncio, há a imagem de uma garrafa em pé, do tipo PET, da qual sai uma "nuvem" de mosquitos, caracterizando a garrafa como criadouro para larvas do Aedes aegypti.

Na parte inferior, há um selo do "Dia D: 6 de dezembro - combate à dengue e chikungunya", seguido, à direita, por três recomendações, na forma de ilustrações e textos indicativos, de eliminação dos criadouros. Abaixo dessas recomendações, há um texto em tamanho reduzido, no qual são explanadas informações sobre as doenças e sobre o dia dedicado ao combate. Finalizando, há as logomarcas do SUS e do governo federal; entre elas, o texto do Ministério da Saúde.

A análise do heat map (Figura 5) permite identificar que a atenção visual dos participantes foi bem distribuída ao longo do anúncio, sem, contudo, ocasionar uma visualização superficial da campanha, já que há pontos de coloração avermelhada no título, na imagem e na região inferior do anúncio. Tal fato pode ser explicado pela organização de um layout bem estruturado e pouco poluído, que facilitou o percurso da leitura. Esse "conforto visual" permitiu, pois, que os itens fossem visualizados atenta e facilmente.

Um aspecto negativo a ser observado é a baixa atenção dada a dois dos três itens que identificam os anunciantes da peça: a logomarca do 
SUS e o texto do Ministério da Saúde (primeira e segundo à esquerda, respectivamente), que passaram praticamente desapercebidos pelos participantes. O item mais observado foi a logomarca que identifica o governo federal, sugerindo que a percepção desse anunciante já foi suficiente para os participantes compreenderem qual era o enunciador da mensagem, sem realizarem maior esforço atencional.
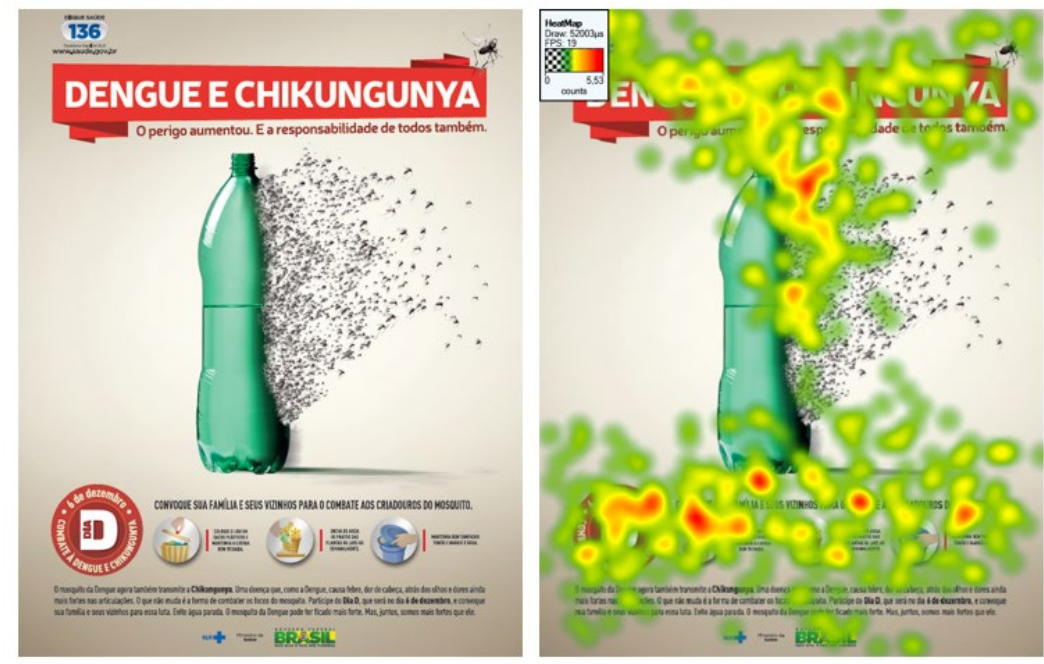

Figura 5 - À esquerda, campanha veiculada pelo governo federal. À direita, heat map da atenção visual dos participantes.

Discutidos os dados exploratórios qualitativos, a próxima seção vai apresentar os dados quantitativos sobre a percepção de título, imagem e anunciante.

\section{Análise quantitativa: título, imagem principal e anunciante}

\section{Títulos das campanhas}

Considerando o planejamento de composição de um anúncio impresso, espera-se que o leitor não demore para encontrar o título da campanha, uma vez que uma de suas funções é, justamente, chamar a atenção para a mensagem apresentada. Nesse sentido, a campanha que obteve melhor resultado foi a de autoria do governo federal, cujos leitores demoraram apenas 0,31 segundos, em média, até focarem, pela primeira vez, o título (Gráfico 1). Tal desempenho é especialmente importante se comparado a outras campanhas que tiveram um tempo médio maior, mesmo com um tamanho da família tipográfica (tipo de letra) maior no título, indicando que, isoladamente, o tamanho não garante uma atenção mais rápida.

Outro destaque foi a campanha do Tribunal de Justiça do Amapá, cujo tempo para a primeira visualização do título foi o mais longo de todos, 0,73 segundos. Isso pode ser explicado pela localização da logomarca do anunciante antes do título, fazendo que os leitores a observassem em primeiro lugar. Quanto ao tempo despendido para a leitura do título, a campanha com maior tempo de visualização foi a da prefeitura de Igarapé-Miri, com média de 3,43 segundos. Isso pode ter ocorrido pelo fato de que, diante de muitos itens dispostos desorganizadamente no restante do anúncio, o leitor sentiu necessidade de dar mais atenção ao título para compreender do que tratava a mensagem em questão. 


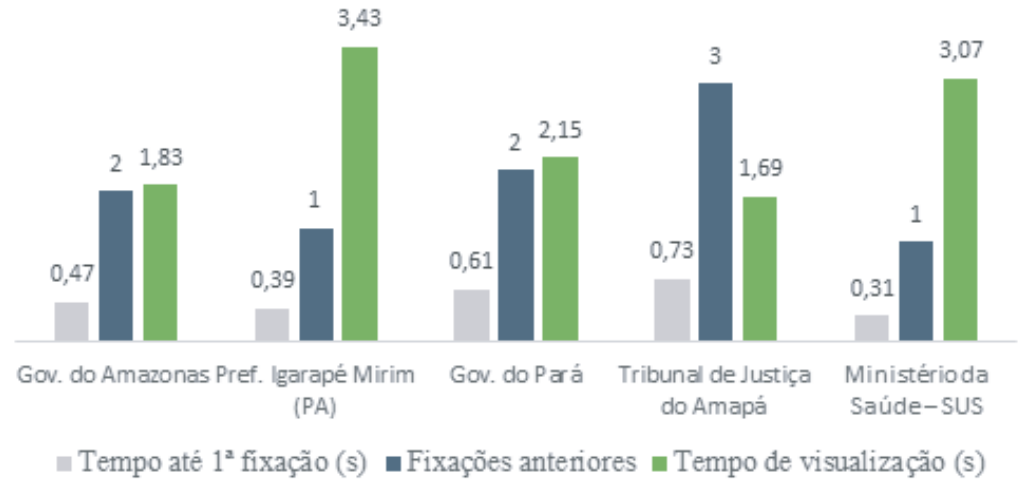

Gráfico 1 - Comparação entre os títulos das campanhas. Fonte: elaborado pelos autores.

\section{Atenção destinada à imagem}

No que se refere à atenção dada à imagem principal das campanhas, a peça da prefeitura de Igarapé-Miri teve um desempenho bastante baixo. Isso porque espera-se que a imagem, enquanto elemento-chave para atrair a atenção do público-alvo para a campanha, seja visualizada rapidamente e por um período de tempo razoável. O Gráfico 2 mostra justamente 0 contrário: foi o maior tempo demandado, entre todas as campanhas, para que o leitor olhasse a imagem do mosquito (6,73 segundos). Ainda, antes de focarem a imagem, os participantes miraram, em média, outros 23 pontos do anúncio, um número muito alto quando se almeja uma rápida captação da atenção.

A campanha do Ministério da Saúde, por sua vez, obteve o melhor resultado: tempo médio até a visualização praticamente nulo $(0,01$ segundos); nenhuma fixação em outra área antes da imagem; e tempo de visualização da imagem de quase 4 segundos, bastante superior aos demais.

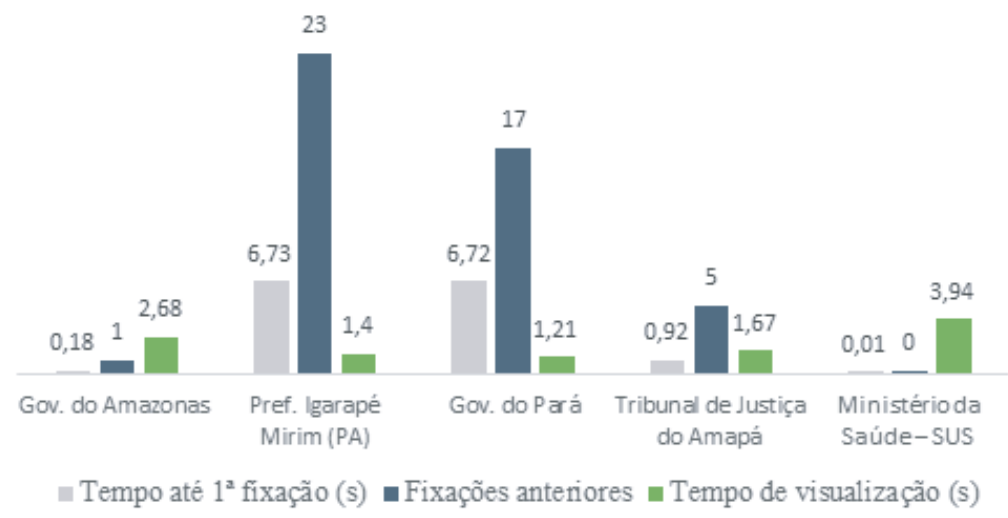

Gráfico 2 - Comparação entre as imagens das campanhas. Fonte: elaborado pelos autores.

\section{Atenção dada ao anunciante}

Diferentemente do que ocorreu na análise dos dois itens anteriores (título e imagem), os anunciantes menos vistos foram os da campanha do governo federal: o SUS, o Ministério da Saúde e o próprio governo federal, cujas logomarcas foram vistas apenas por três dos doze participantes. 
As campanhas que obtiveram maiores índices de visualização nesse quesito foram a do TJ do Amapá e a de Igarapé-Miri. Em ambas, os anunciantes foram observados por onze dos doze indivíduos. A explicação do resultado, contudo, é diferente para cada uma das mensagens. No caso da campanha amapaense, a localização da logomarca na região superior da peça, acima do próprio título, fez que ela fosse percebida sem dificuldades pelos participantes, que levaram apenas 1,91 segundos para iniciar sua leitura.

O fato de a segunda campanha ter tido o mesmo índice de visualização pode ser atribuído à grande área destinada à exposição das marcas envolvidas, e à elevada quantidade de anunciantes (seis), o que pode ter contribuído para captar a atenção dos participantes. Ainda sobre essa campanha, nota-se, no Gráfico 2, que os leitores focaram, em média, 68 pontos da peça, durante cerca de 21 segundos, antes de visualizarem os anunciantes. Uma vez neles, o tempo de leitura foi de 2,46 segundos.

Por fim, a logomarca do governo do Amazonas captou a atenção de oito dos doze participantes, e a do governo do Pará, de apenas um terço dos voluntários. O Gráfico 3 apresenta o resultado das métricas de tempo até a primeira fixação, fixações anteriores e tempo de visualização para cada caso.

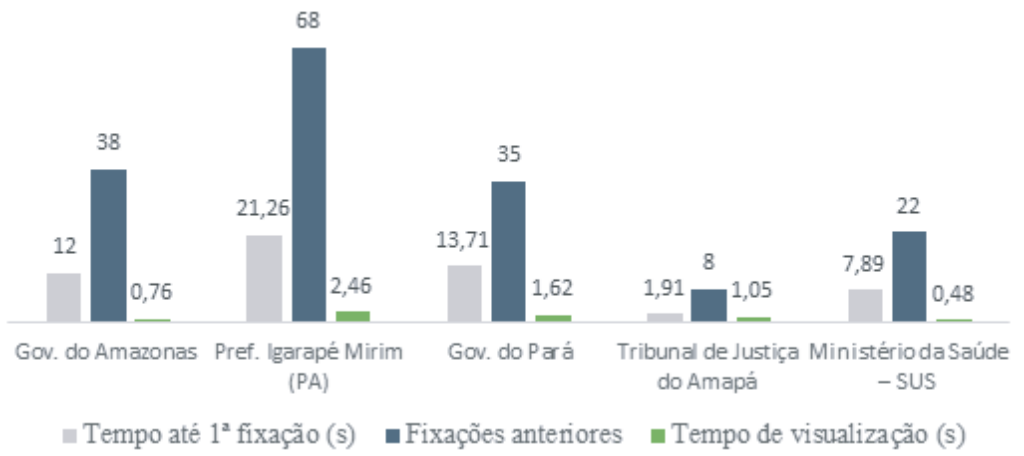

Gráfico 3 - Visualização dos anunciantes das campanhas.

Fonte: elaborado pelos autores.

\section{CONSIDERAÇÕES FINAIS}

Apresentados os resultados, três importantes considerações emergem desta pesquisa. A primeira é que as campanhas de saúde, inseridas no âmbito da comunicação de risco, devem ser melhor estudadas e compreendidas no que se refere a planejamento, composição e eficácia de suas ações, dada a importância dessas campanhas, que, diferentemente das mercadológicas, quase nunca admitem erros, por lidarem com riscos à vida e envolverem investimento de dinheiro público.

Em segundo lugar, a metodologia do eye tracker se mostrou bastante útil e pertinente para a realização desses estudos, tanto de forma qualitativa como quantitativa, uma vez que criou uma valiosa gama de dados, livres de vieses e imprecisões característicos das formas tradicionais de pesquisa em comunicação, como eventuais esquecimentos por parte dos participantes ao fornecerem, por exemplo, dados autodeclarados.

Por fim, os resultados evidenciaram que a composição do layout (forma) e os conteúdos escolhidos para as mensagens impactam diretamente a forma como o público-alvo visualiza (ou não) os itens 
de determinada campanha. Nesse sentido, a localização do anunciante na região superior do anúncio demonstrou melhores resultados se comparados à inserção no rodapé da mensagem. Ainda, uma campanha com espaços vazios (como a do governo federal) permitiu uma orientação visual mais fluida, capaz de gerar menos confusões na ordem da leitura.

De forma complementar, estudos futuros podem ser delineados levando em consideração aspectos contextuais e culturais (uma limitação deste trabalho), para que se possa, posteriormente, conjugar tais resultados a uma análise holística do processo comunicacional.

\section{REFERÊNCIAS}

ALECRIM, J. S.; COTTA, A.; CASTRO, J. M. Relação entre as ações de prevenção da dengue e o impacto causado sobre os casos notificados no município de lpatinga entre os anos de 2009 e 2010. Journal of Health Sciences, Londrina, v. 18, n. 4, p. 286-290, 2016.

BIEL, S. L. Percepção de fatores e situações de risco em motoristas infratores. São Bernardo do Campo: UMESP, 2007.

BRASEL, A.; GIPS, J. Breaking through fast-forwarding: brand information and visual attention. Journal of Marketing, Cambridge, v. 72, n. 6, p. 31-48, 2008.

BRASIL. Ministério da Saúde. Prevenção e combate: dengue, chikungunya e zika. 2016. Disponível em: <https://goo.gl/J831wH >. Acesso em: 24 set. 2017.

BRASIL. Ministério da Saúde. Monitoramento dos casos de dengue, febre de chikungunya e febre pelo vírus Zika até a Semana Epidemiológica 15, 2017. Boletim Epidemiológico, Brasília, v. 48, n. 14, 2017.

CASAQUI, V. Por uma teoria da publicização: transformações no processo publicitário. In: CONGRESSO BRASILEIRO DE CIÊNCIAS DA COMUNICAÇ̃̃O, 34., 2011, Recife. Anais... São Paulo: Intercom, 2011. p. 1-15.

DI NALLO, E. Meeting points: soluções de marketing para uma sociedade complexa. São Paulo: Cobra, 1999.

DREZE, X.; HUSSHERR, F. X. Internet advertising: is anybody watching? Journal of Interactive Marketing, Amsterdam, v. 17, n. 4, p. 8-23, 2003.

D’YDEWALLE, G.; TAMSIN, F. On the visual processing and memory of incidental information: advertising panels in soccer games. In: GALE, A. G.; CARR, K.; BROGAN, D. (Eds.). Visual search 2: proceedings of the 2 nd International Conference on Visual Search. Abingdon: CRC, 1993. p. 401-408.

FERREIRA, M. F. A. P. L. Televisão e dengue: informação e impacto para os telespectadores. 2005. Trabalho de Conclusão de Curso (Graduação em Jornalismo) - Faculdade Assis Gurgacz, Toledo, 2005.

FERREIRA, A. C.; CHIARAVALLOTI-NETO, F., MONDINI, A. Epidemiologia espacial da dengue em Araraquara, São Paulo, Brasil. Investigação, Franca, v. 15, n. 6, 2016.

GOLDBERG, J. H.; PROBART, C. K.; ZAK, R. E. Visual search of food nutrition labels. Human Factors, New York, v. 41, n. 3, p. 425-437, 1999

JANISZEWSKI, C. The influence of display characteristics on visual exploratory search behavior. Journal of Consumer Research, Chicago, v. 25, n. 3, p. 290-301, 1998.

KRUGMAN, D. M. et al. Do adolescents attend to warnings in cigarette advertising? An eye-tracking approach. Journal of Advertising Research, Oxfordshire, v. 34, p. 39-52, 1994.

LEVEN, W. Zusammenhang zwischen blickverhalten und informationsbearbeitung. In: . Blickverhalten von Konsumenten. Heidelberg: Physica, 1991. v. 30. p. 70-116. Disponível em: <https://goo.gl/2JyQDk>. Acesso em: 24 set. 2017.

LIVERSEDGE, S. P.; GILCHRIST, I. D.; EVERING, S. The Oxford handbook of eye movements. New York: Oxford University Press, 2011. $1048 \mathrm{p}$ 
MATTAR, F. N. Pesquisa de marketing. São Paulo: Atlas, 1997.

NATIONAL RESEARCH COUNCIL. Improving risk communication. Washington DC: National Academy Press, 1989.

PEREZ, C. Signos da marca: expressividade e sensorialidade. São Paulo: Thomson Learning, 2004.

PIETERS, R.; WEDEL, M. Attention capture and transfer in advertising: brand, pictorial, and text-size effects on JSTOR. Journal of Marketing, Cambridge, v. 68, n. 2, p. 36-50, 2004.

PIETERS. R.; WEDEL. M.; BATRA. R. The stopping power of advertising: visual complexity, scene incongruity and message information. Tilburg: University of Tilburg, 2008.

ROBINSON, D. A. The oculomotor control system: a review. Proceedings of the IEEE, [S.I.], v. 56, n. 6, p. 1032-1049, 1968.

ROSBERGEN, E.; PIETERS, R.; WEDEL, M. Visual attention to advertising: a segment-level analysis. Journal of Consumer Research, Chicago, v. 24, n. 3, p. 305-314, 1997.

SAMPIERI, R. H.; COLLADO, C. F.; LUCIO, P. B. Metodologia de pesquisa. 5. ed. São Paulo: McGraw-Hill, 2013.

SILVA, E. C.; MAZZON, J. A. Orientação de marketing social às campanhas de saúde da mulher: uma análise da região do grande $A B C$ paulista. Revista Brasileira de Marketing, São Paulo, v. 14, n. 2, p. 247-259, 2015.

SMITH, T. W. Refining the total survey error perspective. International Journal of Public Opinion Research, Oxford, v. 23, n. 4, p. 464-484, 2011.

TEIXEIRA, T.; WEDEL, M.; PIETERS, R. Moment-to-moment optimal branding in TV commercials: preventing avoidance by pulsing. Ann Arbor: University of Michigan, 2008. 